\title{
Ubiquitin domain proteins in disease
}

\author{
Louise Madsen ${ }^{1}$, Andrea Schulze ${ }^{2}$, Michael Seeger ${ }^{2}$ and Rasmus Hartmann- \\ Petersen*1
}

\author{
Address: ${ }^{1}$ Insitute of Molecular Biology and Physiology, University of Copenhagen, Universitetsparken 13, DK-2100 Copenhagen, Denmark and \\ ${ }^{2}$ Charité - Universitätsmedizin Berlin, Campus Charité Mitte, Institut für Biochemie, Monbijoustr. 2, 10117 Berlin, Germany \\ Email: Michael Seeger - michael.seeger@charite.de; Rasmus Hartmann-Petersen* - rhpetersen@aki.ku.dk \\ * Corresponding author
}

Published: 22 November 2007

BMC Biochemistry 2007, 8(SuppI I):SI doi:I0.II86/I47I-209I-8-SI-SI

This article is available from: http://www.biomedcentral.com/|47I-209I/8/SI/SI

(c) 2007 Madsen et al.; licensee BioMed Central Ltd.

This is an open access article distributed under the terms of the Creative Commons Attribution License (http://creativecommons.org/licenses/by/2.0), which permits unrestricted use, distribution, and reproduction in any medium, provided the original work is properly cited.

\begin{abstract}
The human genome encodes several ubiquitin-like (UBL) domain proteins (UDPs). Members of this protein family are involved in a variety of cellular functions and many are connected to the ubiquitin proteasome system, an essential pathway for protein degradation in eukaryotic cells. Despite their structural similarity, the UBL domains appear to have a range of different targets, resulting in a considerable diversity with respect to UDP function. Here, we give a short summary of the biochemical and physiological roles of the UDPs, which have been linked to human diseases including neurodegeneration and cancer.
\end{abstract}

Publication history: Republished from Current BioData's Targeted Proteins database (TPdb; http://www.targetedproteinsdb.com).

\section{Introduction}

Ubiquitin is a small and phylogenetically conserved eukaryotic protein known to covalently modify proteins and thereby mark them for destruction by the $26 \mathrm{~S}$ proteasome [1]. This process, termed ubiquitylation, is also involved in the regulation of many other cellular processes including endocytosis and transcription [1].

Ubiquitin ligation is accomplished in multiple steps [2], the first of which involves ATP-dependent activation of ubiquitin by a ubiquitin activating enzyme (E1). Second, the activated ubiquitin is transferred to a ubiquitin conjugating enzyme (E2). A ubiquitin protein ligase (E3) then associates with both the ubiquitin-charged E2 and the substrate, facilitating the formation of an isopeptide bond between the C-terminus of ubiquitin and an amino group (typically a lysine residue) either directly on the target protein or on the last ubiquitin moiety of an attached polyubiquitin chain [2]. Several such rounds of conjugation yield substrates carrying chains of ubiquitin moieties, which may be elongated further by the action of a ubiquitin chain elongation factor (E4) [3]. Combinations of E2 and E3 enzymes (of which there are hundreds encoded in the human genome) primarily provide the substrate specificity of the ubiquitylation system [2].

The formation of polyubiquitin chains is a reversible process and several deubiquitylating enzymes (DUBs) play important roles in trimming the chains on target proteins [4].

Different ubiquitin lysine residues are used in the formation of polyubiquitin chains, with various outcomes. For example, whereas Lys48-linked polyubiquitin chains target proteins for degradation by the $2.5 \mathrm{MDa} 26 \mathrm{~S}$ proteasome in an ATP-dependent manner [5], linking through 
Lys63 plays a role in NFkB-signalling and the formation of Lewy bodies in patients with Parkinson's disease [6-8]. Modification of proteins with a single ubiquitin moiety (monoubiquitylation) also plays an important role, namely in endocytosis and transcription [9].

Ubiquitin is a stable and compact protein consisting of two $\alpha$-helices and five $\beta$-strands arranged in the order $\beta \beta \alpha \beta \beta \alpha \beta$ to form the ubiquitin superfold [10]. Recently, several ubiquitin-like proteins have been identified, which despite a relatively low sequence similarity, all display the ubiquitin superfold [11]. These proteins are generally divided into two groups: ubiquitin-like modifiers (UBLs) and ubiquitin-like domain proteins (UDPs) [12]. In addition to ubiquitin itself, the group of UBLs can become covalently attached to substrate proteins in a similar manner to ubiquitylation, and includes proteins such as NEDD8, SUMO, FAT10 and others. Despite their similarities, the assorted UBLs are implicated in different cellular functions [12]. However, we shall not discuss them further here, but instead focus on the group of UDPs.

The UDPs are responsible for recruitment of ubiquitylated substrates to the proteasome [13] and bind to the 26S proteasome in a UBL-dependent manner [14]. Hence, it was thought that the UBL domain is a general proteasome binding domain. However, recently it was demonstrated that some UDPs do not interact with the proteasome [15]. Thus, despite their structural similarities to each other and ubiquitin, UDPs display striking differences on the functional level. Here we give a brief overview of a selection of UDPs involved in human diseases.

\section{UBL/UBA domain proteins}

UDPs that contain one or more ubiquitin binding UBA (ubiquitin-associated) domain (figure 1) in addition to a UBL domain are called UBL/UBA domain proteins. The yeast proteins Rad23 and Dsk2 are the best characterized members of this group.

Precipitation experiments have shown that the UBL domain of both $\operatorname{Rad} 23$ and its human homologue (HHR23) interacts directly with the 26S proteasome in vitro[14], while the UBA domain interacts with ubiquitin [13]. UBL/UBA domain proteins were therefore proposed to function as substrate shuttles, transporting ubiquitylated proteins in the cytosol from E3 enzymes to the 26S proteasome [16]. This shuttle model was recently confirmed in vitro by biochemical experiments, which showed that UBL/UBA proteins are essential for degradation of a proteasome substrate [17]. Since most proteasome substrates, including cell cycle regulators, oncogenes and tumour suppressor proteins [1], are probably directed to the proteasome via the UBL/UBA proteins, drugs targeting these proteins may prove useful in treating cancer.

Despite the fact that none of the UBL/UBA proteins are essential in yeast, combined loss of Rad23, Dsk2 and the proteasome's ubiquitin receptor Rpn10/S5a results in mitotic arrest [13]. This indicates that though UBL/UBA proteins are redundant and have overlapping substrate specificity, some seem to be relatively specific for certain target proteins. This has already been shown by pulsechase experiments for certain cell cycle-related proteins, such as Sic1 and Cln2 [17]. Therefore, specific rather than general targeting of UBL/UBA proteins could be a more effective approach in cancer therapy.

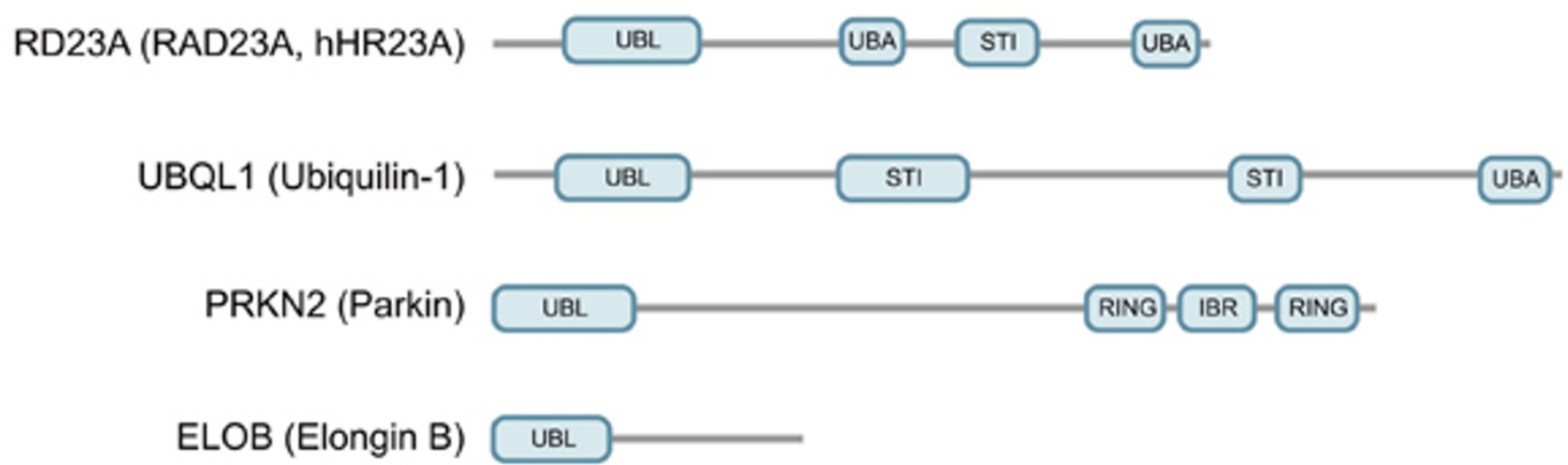

Figure I

Domain organization of selected UBL domain proteins. The figure depicts schematic representations of the domain architecture of selected human UBL domain proteins. The domains are: UBL, ubiquitin-like; UBA, ubiquitin-associated; STI, Stil-like; RING, ring finger; IBR, in-between ring fingers. 
In precipitation experiments the UDPs Rad23, Dsk2 and their human orthologues HHR23 and ubiquilin-1 interact with the $26 \mathrm{~S}$ proteasome in a UBL domain-dependent manner $[13,18,19]$. However, within the $26 \mathrm{~S}$ proteasome, the UDPs appear to have distinct binding preferences. For example, yeast Rad23 and Dsk2 interact with the proteasome subunit Rpn1/S2 [20,21], whereas human HHR23 interacts with the second ubiquitin interaction motif (UIM) of human Rpn10/S5a [18], which is not present in yeast Rpn10/S5a [21].

Both Ufd2 (an E4) and the 26S proteasome associate with the Rad23 UBL domain in a mutually exclusive manner in vitro[22]. One might therefore speculate that Rad23 associates with Ufd2, possibly inhibiting its E4 activity, while binding the ubiquitylated substrate via the UBA domains. Eventually, Rad23 will dissociate from Ufd2 and dock at the $26 \mathrm{~S}$ proteasome, thus delivering the ubiquitylated cargo [23].

In addition to the $26 \mathrm{~S}$ proteasome and ubiquitylated substrate, HHR23 also interacts with ataxin-3 in vitro, a protein involved in the development of the neurodegenerative Machado-Joseph disease [24]. Similar to deubiquitylating enzymes, ataxin-3 contains ubiquitin interaction motifs (UIMs) and a protease domain. Surprisingly, the HHR23 UBL domain was found to interact with the protease domain of ataxin- 3 rather than with one of the UIMs $[24,25]$. Since ataxin-3 also associates with both the proteasome and polyubiquitin chains, it may recruit ubiquitylated substrates to the proteasome [26]. However, ataxin-3 is also a substrate of the E4 enzyme Ufd2 [27] and perhaps of HHR23 [22,23]. Therefore, further studies are necessary to understand the physiological background of the ataxin-3-HHR23 interaction.

\section{UBL/UBA domain proteins in disease Alzheimer's disease}

Ubiquilins 1-4 are human homologues of yeast Dsk2. Ubiquilin-1 and ubiquilin-2 both bind the proteasome [19] and, interestingly, have both been linked to Alzheimer's disease, since they were proposed to bind presenilins and localize to Lewy bodies and neurofibrillar tangles [28]. Moreover, genetic variations in the ubiquilin-1 gene are proposed to substantially increase the risk of developing Alzheimer's disease [29]. The generation of the C-terminus of amyloid $\beta$-protein $(\mathrm{A} \beta$ ) is dependent on presenilins. Mutations in presenilin-1 and presenilin-2 lead to an increased ratio of $\beta$-APP42 to $\beta$-APP40 (also known as $A \beta 42$ and $A \beta 40$ ) from amyloid $\beta$-precursor protein [30]. Accumulation of these $A \beta$ peptides outside the cell leads to amyloid plaques, a major lesion in Alzheimer's disease [31]. The presenilin-ubiquilin interaction was mapped to the C-terminal UBA domain of ubiquilin-1 [28]. However, in these studies, in which ubiquilin fusion proteins were used to precipitate in vitro translated presenilins, SDS-PAGE of the precipitates revealed a slowly migrating smear. It is therefore likely that only ubiquitylated presenilins can interact with ubiquilin-1. It is also possible that ubiquilin-1 only interacts with ubiquitylated $\gamma$-aminobutyric acid A $\left(\mathrm{GABA}_{\mathrm{A}}\right)$ receptors [32].

In order to efficiently transmit synaptic signals, the amount of $\mathrm{GABA}_{\mathrm{A}}$ receptor at inhibitory synapses is tightly regulated $[32,33]$. This is maintained by the internalization of the receptor at clathrin-coated pits [34]. Ubiquilin-1 binds $\mathrm{GABA}_{\mathrm{A}}$ receptors and facilitates their membrane insertion by increasing the stability of the intracellular pool [32]. Based on these data, it is feasible that the UDP only interacts with ubiquitylated $\mathrm{GABA}_{\mathrm{A}}$ receptors. As proteasomal degradation of the receptors was not observed, ubiquilin-1 may therefore also function in endocytosis [32]. Accordingly, it has been reported that ubiquilin-1 interacts with Eps15, an essential component of the clathrin-mediated endocytic pathway [35]. Eps15 contains two UIMs, and ubiquilin- 1 binds to the one that is closer to the N-terminus. Besides Eps15, other UIMcontaining proteins linked to the endocytic pathway also bind the UBL domain of ubiquilin-1 [35]. Although these proteins co-localize with ubiquilin-1, they were not found in endocytic compartments, but in cytoplasmic aggregates or aggresomes. Thus, ubiquilin-1 may be involved in the sequestration of certain UIM-containing endocytic proteins to ubiquitin-rich aggregates [35]. This is consistent with the finding that ubiquilin-1 and ubiquilin-2 localize to ubiquitin-positive structures and are both present in aggresomes [36]. It is possible that ubiquilin-1 targets aggregated, ubiquitylated proteins as well as UIM-containing endocytic proteins to aggresomes. This hypothesis was recently strengthened by knockdown and overexpression studies that revealed a possible dual function of the ubiquilin-1 UBL domain [37]. These studies suggest that under low levels of polyglutamine protein aggregation, ubiquilin-1 shuttles ubiquitylated proteins to the proteasome, while under higher levels of protein aggregation, the proteasome may become overloaded and alternative functions of the ubiquilin UBL domain enhanced, for example, interaction with Eps15 to promote trafficking of protein aggregates to the aggresomes (figure 2) [37]. Once the aggregated proteins reach the aggresome, their toxicity is reduced by their efficient autophagic removal [38].

\section{Spinocerebellar ataxia}

Ubiquilin-4 is linked to spinocerebellar ataxia type 1 (SCA1) [39], an inherited neurodegenerative disease, which primarily affects the brainstem, spinocerebellar tracts and cerebellar Purkinje cells. The disease is caused by an expansion of a polyglutamine stretch within the SCA1 protein, ataxin-1. Similar to other UBL/UBA proteins, ubiquilin- 4 binds the proteasome subunit Rpn10/ 


\section{a) Low Aggregation}

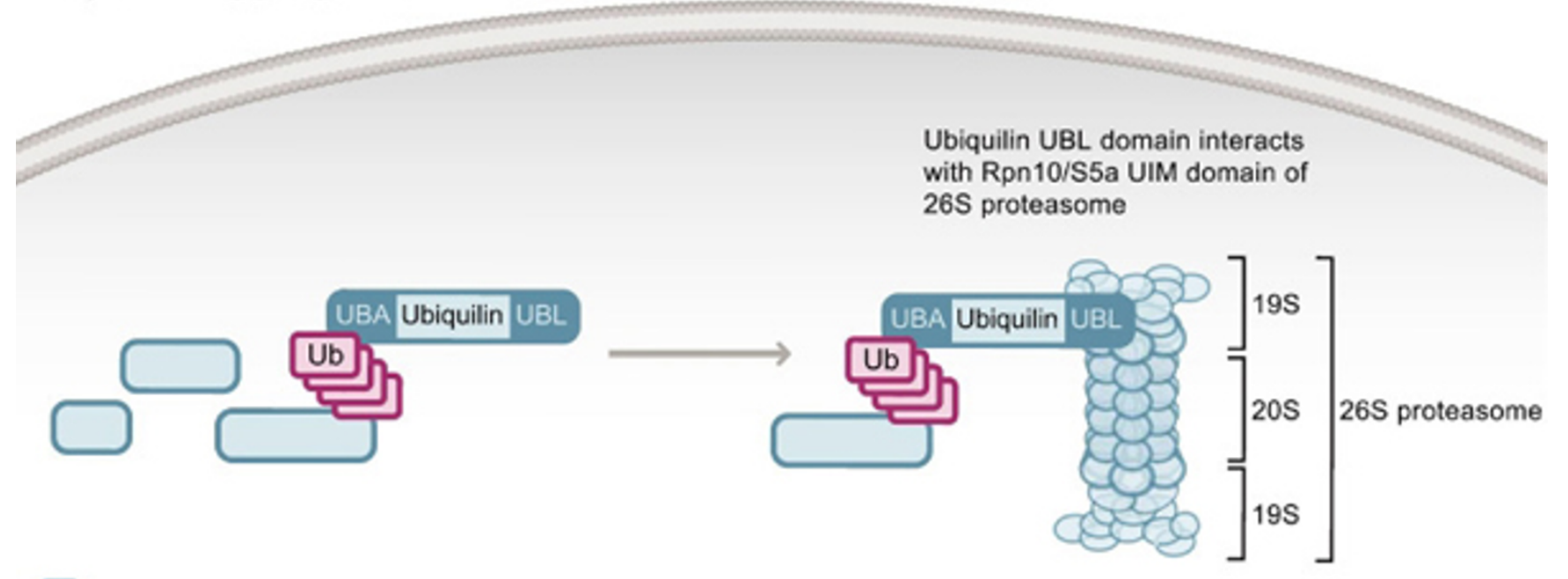

\section{b) High Aggregation and Overloading of Proteasome}

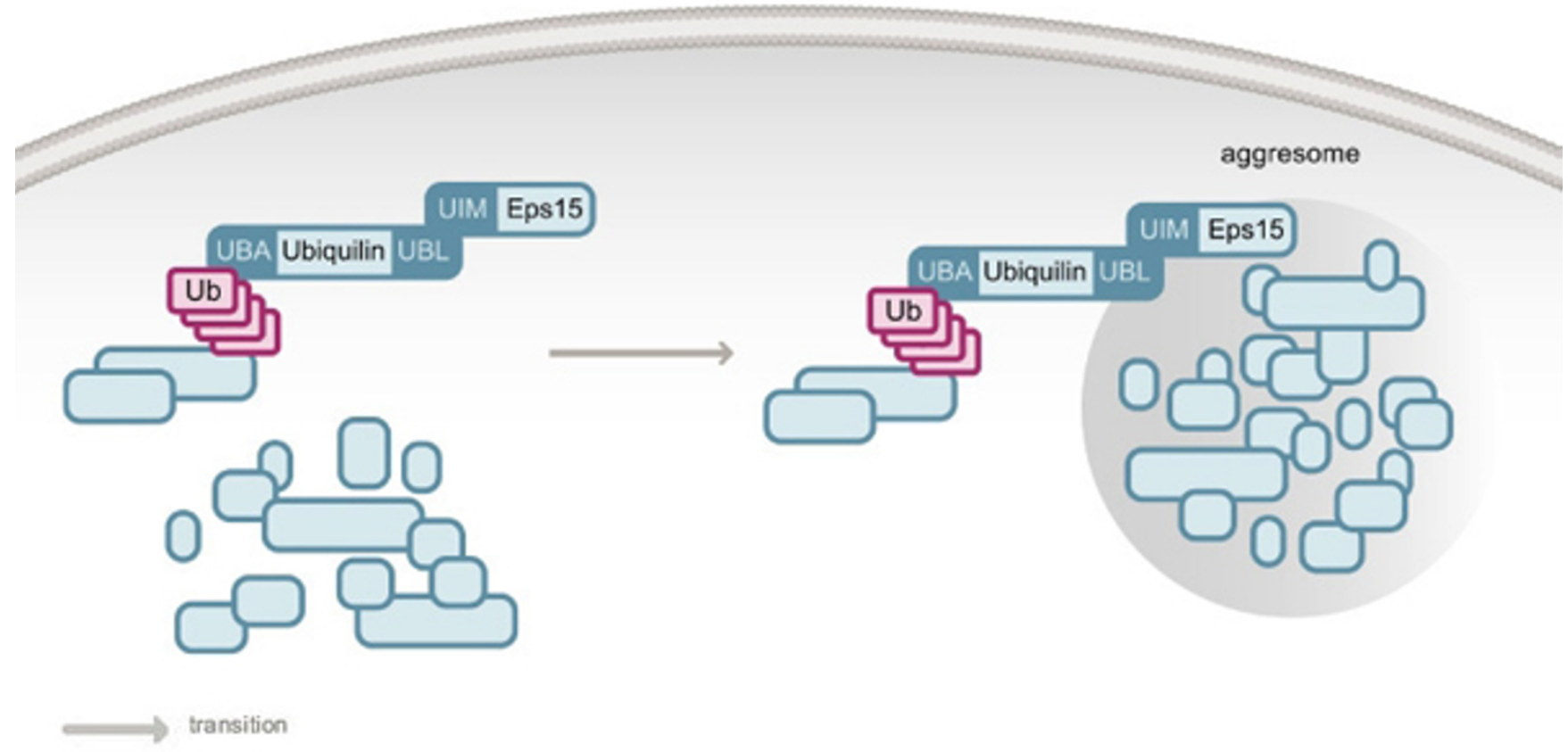

\section{Figure 2}

The role of ubiquilin in protein degradation in mammalian cells. Under normal conditions, when only low amounts of protein aggregates are present in cells (a), ubiquilin shuttles ubiquitylated proteins to the $26 \mathrm{~S}$ proteasome via a UBL-dependent interaction with the Rpn I0/S5a UIM domain. When cells contain larger amounts of aggregated protein (b), the proteasome becomes overloaded, leaving the ubiquilin UBL domain to interact with other cellular UIM proteins. These include Eps 15, which instead promotes transport of aggregation-prone proteins to the aggresome. The figure is based on the model of Heir et al.[37]. 
S5a via its UBL domain and polyubiquitin chains via its UBA domain $[39,40]$.

\section{Juvenile Parkinsonism}

Autosomal recessive juvenile Parkinsonism (AR-JP) is an early onset and slowly progressing disease, the most common cause for which is mutations in the PARK2 gene encoding PRKN2 (also known as parkin) [41-43]. PRKN2 contains a UBL domain and two E3-type RING-finger motifs (figure 1), and localises to the cytoplasm and centrosome/aggresome [44]. Accordingly, it was shown that PRKN2 is a functional E3 and that pathological mutations in PARK2 impair its catalytic activity [45-47]. Several PRKN2 substrates have been identified, including the synaptic vesicle-associated GTPase CD-Crel-1, Cyclin-E, the $\alpha$-synuclein-interacting protein synphilin, PaelRl and glycosylated $\alpha$-synuclein [46,48-51]. Thus, loss of PRKN2 may result in the accumulation of its substrates, leading to the death of dopaminergic neurons. Supporting evidence comes from experiments in which over-expression of the PRKN2 substrate PAELR1 led to cell death in neuroblastoma cells, an effect which could be rescued by wild-type but not mutant PRKN2. [49]. Moreover, glycosylated $\alpha$ synuclein was found to accumulate in the brain of PRKN2-deficient AR-JP patients [50].

Although most of the pathogenic missense mutations cluster to the RING domain-containing C-terminus of PRKN2, a few mutations have also been identified in the UBL region. NMR interaction studies have identified an interaction between the PRKN2 UBL domain and the proteasome subunit Rpn10/S5a, an observation not made with the pathogenic PRKN2 mutant R42P [52]. However, since in vitro precipitation assays failed to confirm the interaction [52], its significance is questionable. More recent evidence lends support to these doubts, since it was shown by immunoblotting that PRKN2 catalyses Lys63linked ubiquitylation of synphilin-1 in vivo[53]. Though Lys63-linked polyubiquitin chains can support proteasomal degradation [54,55], this type of modification is also associated with endocytosis [56], indicating that perhaps PRKN2 exhibits proteasome-independent functions. Additionally, precipitation experiments demonstrated that PRKN2 binds Eps15 in a UBL domain-dependent manner [57]. Upon treating fibroblasts with epidermal growth factor (EGF), PRKN2 mediates ubiquitylation of Eps15 and thereby delays internalization of the EGFreceptor (EGFR). In PRKN2-deficient cells, however, endocytosis of EGFR is accelerated. Since EGFR stimulates neuronal survival via Akt pathway signalling, its accelerated endocytosis in mutant cells may lead to inefficient Akt signalling and reduced neuronal survival, resulting in AR-JP [57].
PRKN2 can also be destabilized by pathogenic mutations within its UBL domain [58]. However, a truncated version of PRKN2, without the UBL domain, was dramatically stabilised when compared with full-length PRKN2. The first six residues of the UBL domain were found to be responsible for destabilizing PRKN2 [59]. Thus, the PRKN2 UBL domain harbours a destabilization signal responsible for its rapid turnover. Interestingly, there is a truncated PRKN2 isoform in humans, synthesized from an internal start codon, which lacks the UBL domain. The functional significance of this PRKN2 isoform and its stability is still unclear.

\section{Von Hippel-Lindau disease}

Von Hippel-Lindau (VHL) disease is an autosomal dominant cancer, which manifests as angiomas of the retina, hemangioblastomas of the CNS and renal clear cell carcinomas [60]. Patients with VHL disease harbour a germ line mutation in one allele of the tumour suppressor gene encoding the nuclear and cytoplasmic VHL protein [60]. VHL is the substrate binding component of the multisubunit E3 CBCVHL (Cullin-Elongin-BC-VHL) [61]. In addition to $\mathrm{VHL}$, the $\mathrm{E} 3$ complex contains the structural component Cullin-2, the catalytic subunit RBX1 (ROC1) and Elongin-B and $-\mathrm{C}$ [61].

$\mathrm{CBC}^{\mathrm{VHL}}$ catalyses the ubiquitylation of hypoxia-inducible transcription factor $\alpha$ (HIF $\alpha$ and several other substrates $[62,63]$. Under normoxic conditions, HIF $\alpha$ is ubiquitylated by the $\mathrm{CBC}^{\mathrm{VHL}}$ complex, leading to low levels of HIF $\alpha$ and therefore moderate expression of HIF $\alpha$ target genes [61]. Inactivation of VHL causes accumulation of $\mathrm{HIF} \alpha$, leading to increased transcription of HIF $\alpha$ target genes, most of which are angiogenic factors. This in turn causes extensive proliferation of capillaries, a crucial step in tumour development in VHL disease [61].

Elongin- $\mathrm{B}$ and $-\mathrm{C}$ are also found in other $\mathrm{CBCs}$, where they either link other VHL-box proteins and Cullin-2, or SOCS-box proteins and Cullin-5 [64]. Additional functions of Elongin- $\mathrm{B}$, besides its role as adapter component of CBCs, are yet to be documented, as are the functions of its UBL domain (figure 1).

\section{UDP disease models}

Yeast has proved to be an excellent model system for the study of the UBL/UBA proteins. However, developing transgenic mouse models will further reveal important functional aspects of their molecular functions. A knockout is already available in Rad23b (Mhr23b), the murine orthologue of RAD23B (HHR23B) [65], which displays impaired embryonic development and a high rate of neonatal death. In surviving animals, a variety of abnormalities are observed, including retarded growth, facial dysmorphology and male sterility [65]. 
To date, two Park2 knockout mouse models have been reported $[66,67]$, both of which are viable and fertile. The morphology and viability of dopaminergic neurons in both strains was also unaltered, even in aged animals, though behavioural abnormalities including a reduced exploratory behaviour were observed. Moreover, the mouse mutant model Quaking has been reported as a spontaneous Park2 knockout, which additionally lacks the PRKN2 co-regulated gene Pacrg[68]. Homozygote quaking mutants are characterised by dysmyelination in the CNS, resulting in phenotypes including movement disorders, tremors and seizures [68].

In Drosophila, the loss of park (homologue of PARK2) results in reduced cell size and number, infertility, reduced lifespan, movement and flying disorders, and increased sensitivity to oxidative stress [69]. However, even as adults, these park mutant flies do not display agedependent neuron loss in the brain.

Collectively, the mouse and Drosophila PRKN2 models will serve as an invaluable tool for understanding the biological role of PRKN2 and may provide important clues to the molecular mechanisms of Parkinson's disease.

\section{UDPs as drug targets}

Inhibitors of the $26 \mathrm{~S}$ proteasome, such as bortezomib, are successfully being used in the treatment of certain cancers [70]. However, drug targeting of UDPs certainly has several potential advantages over the use of proteasome inhibitors since such drugs would likely be more specific.

Devising efficient inhibitors for non-enzymatic proteins such as the UBL/UBA proteins is more difficult than for proteins with enzyme activity, which can be assayed in high-throughput screens. Nonetheless, recent chemical genetic screens in Xenopus extracts performed by Verma et $a l$. at Caltech have identified a group of relatively small molecules, called ubistatins, which inhibit the turnover of cyclin-B and the cdk-inhibitor Sic1 in vitro by inhibiting the binding of ubiquitylated proteins to substrate shuttles [71]. Accordingly, biochemical assays revealed that the ubiquitin-independent degradation of the proteasome substrate ornithine decarboxylase is not affected by ubistatins indicating that ubistatins may provide a more specific alternative to proteasome inhibitors in cancer treatment. A much more detailed knowledge of the specificity of UBL/UBA proteins and other proteasome co-factors will be necessary before development of drugs targeting UBL/UBA proteins can occur and thus alleviate the neurological disorders associated with these proteins.

As for many loss-of-function mutations in disease-connected E3 enzymes, it is difficult to envision small molecules that could reactivate the mutant PRKN2 and thereby promote neuronal survival in patients suffering from ARJP. However, a gene therapeutic approach to replace the dysfunctional PARK2 gene with a wild-type copy could perhaps provide a cure in the future.

In the case of von Hippel-Lindau disease, small molecule activators of mutant VHL may be able to sustain HIFa degradation and prevent tumour angiogenesis. However, it was found that the molecular chaperone Hsp90 protects certain VHL substrates from proteasomal degradation [72] and cycloheximide decay assays revealed that HIF $\alpha$ is degraded by a VHL-independent mechanism in the presence of Hsp90 inhibitors [73]. Hsp90 inhibitors, such as benzoquinone ansamycin 17-allylamino-17-desmethoxygeldanamycin (17-AAG), could therefore be exploited in the treatment of patients with renal carcinomas, an idea currently being assessed in multi-institutional phase I trials [73]. For a review on Hsp90 inhibitors in drug development, please refer to Maloney and Workman [74].

\section{New frontiers in drug discovery}

It is evident that the UBL/UBA proteins and PRKN2 appear to be directly involved in the etiology of cancer and neurodegenerative diseases. Although this is by no means a general feature of the UDPs, it highlights the importance of the ubiquitin system in maintaining an appropriate intracellular protein milieu.

With respect to the UBL/UBA proteins, one major issue that remains unresolved relates to their specificity. Though some details of their substrate selectivity have emerged [17], a more comprehensive picture is needed in order to fully validate them as drug targets. The same is the case for many of the other UDPs encoded in the human genome [11], some of which may also be involved in human disease.

In relation to PRKN2, identifying novel substrates of its E3 activity and resolving its proteasome-dependent and/or independent functions (especially relating to endocytosis, trafficking and signalling via Eps15) may shed some light on the molecular mechanism of Parkinson's disease and hopefully lead to novel therapeutic approaches.

\section{Abbreviations}

$\mathrm{A} \beta$, amyloid $\beta$-protein; AR-JP, autosomal recessive juvenile parkinsonism; $\mathrm{CBC}$, Cullin-Elongin- $\mathrm{BC}$; $\mathrm{DUB}$, deubiquitylating enzyme; EGF, epidermal growth factor; EGFR, epidermal growth factor receptor; $\mathrm{GABA}_{A^{\prime}} \gamma$-aminobutyric acid $\mathrm{A} ; \mathrm{HIF} \alpha$, hypoxia-inducible transcription factor $\alpha$; SCA1, spinocerebellar ataxia type 1; UBA, ubiquitin-associated domain; UBL, ubiquitin-like; UDP, UBL domain protein; UIM, ubiquitin-interacting motif; $\mathrm{VHL}$, von Hippel-Lindau. 


\section{Competing interests}

The authors declare that they have no competing interests.

\section{Acknowledgements}

We apologize to those whose work we were unable to cite due to space constraints. M.S. is supported by a grant from the Deutsche Forschungsgemeinschaft (SE 938/3-I) and R.H.-P. by grants from the Danish Natural Science Research Council and the Lundbeck Foundation.

This article has been published as part of BMC Biochemistry Volume 8 Supplement I, 2007: Ubiquitin-Proteasome System in Disease Part I. The full contents of the supplement are available online at http://www.biomedcen tral.com/|47|-209|/8?issue=SI.

\section{References}

I. Glickman $\mathrm{MH}$, Ciechanover A: The ubiquitin-proteasome proteolytic pathway: destruction for the sake of construction. Physiol Rev 2002, 82:373-428.

2. Pickart CM: Mechanisms underlying ubiquitination. Annu Rev Biochem 2001, 70:503-533.

3. Koegl M, Hoppe T, Schlenker S, Ulrich HD, Mayer TU, Jentsch S: A novel ubiquitination factor, $\mathrm{E4}$, is involved in multiubiquitin chain assembly. Cell 1999, 96:635-644.

4. Wilkinson KD: Ubiquitination and deubiquitination: targeting of proteins for degradation by the proteasome. Semin Cell Dev Biol 2000, I I:|4|-| 48 .

5. Deveraux Q, Ustrell V, Pickart C, Rechsteiner M: A 26 S protease subunit that binds ubiquitin conjugates. J Biol Chem 1994, 269:7059-706I.

6. Thrower JS, Hoffman L, Rechsteiner M, Pickart CM: Recognition of the polyubiquitin proteolytic signal. Embo J 2000, 19:94-102.

7. Deng L, Wang C, Spencer E, Yang L, Braun A, You J, Slaughter C, Pickart $C$, Chen ZJ: Activation of the IkappaB kinase complex by TRAF6 requires a dimeric ubiquitin-conjugating enzyme complex and a unique polyubiquitin chain. Cell 2000, 103:35I-36I.

8. Lim KL, Chew KC, Tan JM, Wang C, Chung KK, Zhang Y, Tanaka Y, Smith W, Engelender S, Ross CA, Dawson VL, Dawson TM: Parkin mediates nonclassical, proteasomal-independent ubiquitination of synphilin-I: implications for Lewy body formation. J Neurosci 2005, 25:2002-2009.

9. Hicke L: Protein regulation by monoubiquitin. Nat Rev Mol Cell Biol 200I, 2: |95-20I.

10. Vijay-Kumar S, Bugg CE, Cook WJ: Structure of ubiquitin refined at $\mathrm{I.8} \AA$ resolution. J Mol Biol 1987, 194:531-544.

II. Hartmann-Petersen R, Gordon C: Integral UBL domain proteins: a family of proteasome interacting proteins. Semin Cell Dev Biol 2004, 15:247-259.

12. Jentsch S, Pyrowolakis G: Ubiquitin and its kin: how close are the family ties? Trends Cell Biol 2000, 10:335-342.

13. Wilkinson CR, Seeger M, Hartmann-Petersen R, Stone M, Wallace M, Semple C, Gordon C: Proteins containing the UBA domain are able to bind to multi-ubiquitin chains. Nat Cell Biol 200I, 3:939-943

14. Schauber C, Chen L, Tongaonkar P, Vega I, Lambertson D, Potts W, Madura K: Rad23 links DNA repair to the ubiquitin/proteasome pathway. Nature 1998, 391:715-718.

15. Schulze A, Standera S, Buerger E, Kikkert M, van Voorden S, Wiertz $E$, Koning F, Kloetzel PM, Seeger M: The ubiquitin-domain protein HERP forms a complex with components of the endoplasmic reticulum associated degradation pathway. J Mol Biol 2005, 354: $1021-1027$.

16. Hartmann-Petersen R, Seeger M, Gordon C: Transferring substrates to the $26 \mathrm{~S}$ proteasome. Trends Biochem Sci 2003, 28:26-3I.

17. Verma R, Oania R, Graumann J, Deshaies RJ: Multiubiquitin chain receptors define a layer of substrate selectivity in the ubiquitin-proteasome system. Cell 2004, I I 8:99-I I0.

18. Hiyama H, Yokoi M, Masutani C, Sugasawa K, Maekawa T, Tanaka K, Hoeijmakers JH, Hanaoka F: Interaction of hHR23 with S5a. The ubiquitin-like domain of hHR23 mediates interaction with
S5a subunit of 26 S proteasome. I Biol Chem 1999, 274:28019-28025.

19. Kleijnen MF, Shih AH, Zhou P, Kumar S, Soccio RE, Kedersha NL, Gill G, Howley PM: The hPLIC proteins may provide a link between the ubiquitination machinery and the proteasome. Mol Cell 2000, 6:409-419.

20. Elsasser S, Gali RR, Schwickart M, Larsen CN, Leggett DS, Muller B Feng MT, Tubing F, Dittmar GA, Finley D: Proteasome subunit Rpn I binds ubiquitin-like protein domains. Nat Cell Biol 2002, 4:725-730.

21. Seeger M, Hartmann-Petersen R, Wilkinson CR, Wallace M, Samejima I, Taylor MS, Gordon C: Interaction of the anaphase-promoting complex/cyclosome and proteasome protein complexes with multiubiquitin chain-binding proteins. J Biol Chem 2003, 278: $1679 \mid-16796$.

22. Kim I, Mi K, Rao H: Multiple interactions of Rad23 suggest a mechanism for ubiquitylated substrate delivery important in proteolysis. Mol Biol Cell 2004, I 5:3357-3365.

23. Richly H, Rape M, Braun S, Rumpf S, Hoege C, Jentsch S: A series of ubiquitin binding factors connects CDC48/p97 to substrate multiubiquitylation and proteasomal targeting. Cell 2005, 1 20:73-84.

24. Wang G, Sawai N, Kotliarova S, Kanazawa I, Nukina N: Ataxin-3, the MJDI gene product, interacts with the two human homologs of yeast DNA repair protein RAD23, HHR23A and HHR23B. Hum Mol Genet 2000, 9: I795-| 803.

25. Nicastro G, Menon RP, Masino L, Knowles PP, McDonald NQ, Pastore $A$ : The solution structure of the Josephin domain of ataxin-3: structural determinants for molecular recognition. Proc Natl Acad Sci U S A 2005, 102:10493-10498.

26. Doss-Pepe EW, Stenroos ES, Johnson WG, Madura K: Ataxin-3 interactions with rad23 and valosin-containing protein and its associations with ubiquitin chains and the proteasome are consistent with a role in ubiquitin-mediated proteolysis. Mol Cell Biol 2003, 23:6469-6483.

27. Matsumoto $M$, Yada M, Hatakeyama S, Ishimoto $H$, Tanimura T, Tsuji S, Kakizuka A, Kitagawa M, Nakayama KI: Molecular clearance of ataxin-3 is regulated by a mammalian E4. Embo J 2004, 23:659-669.

28. Mah AL, Perry G, Smith MA, Monteiro MJ: Identification of ubiquilin, a novel presenilin interactor that increases presenilin protein accumulation. / Cell Biol 2000, I5 I:847-862.

29. Bertram L, Hiltunen M, Parkinson M, Ingelsson M, Lange C, Ramasamy K, Mullin K, Menon R, Sampson AJ, Hsiao MY, Elliott KJ, Velicelebi G, Moscarillo T, Hyman BT, Wagner SL, Becker KD, Blacker D, Tanzi RE: Family-based association between Alzheimer's disease and variants in UBQLNI. N Engl J Med 2005, 352:884-894.

30. Blennow K, de Leon MJ, Zetterberg H: Alzheimer's disease. Lancet 2006, 368:387-403

31. Selkoe DJ: Cell biology of protein misfolding: the examples of Alzheimer's and Parkinson's diseases. Nat Cell Biol 2004, 6:1054-1061.

32. Bedford FK, Kittler JT, Muller E, Thomas P, Uren JM, Merlo D, Wisden W, Triller A, Smart TG, Moss SJ: GABA(A) receptor cell surface number and subunit stability are regulated by the ubiquitin-like protein Plic-I. Nat Neurosci 2001 4:908-916.

33. Macdonald RL, Olsen RW: GABAA receptor channels. Annu Rev Neurosci 1994, I 7:569-602.

34. Kittler JT, Delmas P, Jovanovic JN, Brown DA, Smart TG, Moss SJ: Constitutive endocytosis of GABAA receptors by an association with the adaptin AP2 complex modulates inhibitory synaptic currents in hippocampal neurons. J Neurosci 2000 , 20:7972-7977.

35. Regan-Klapisz E, Sorokina I, Voortman J, de Keizer P, Roovers RC, Verheesen $P$, Urbe S, Fallon L, Fon EA, Verkleij A, Benmerah A, van Bergen en Henegouwen PM: Ubiquilin recruits Eps 15 into ubiquitin-rich cytoplasmic aggregates via a UIM-UBL interaction. J Cell Sci 2005, I I 8:4437-4450

36. Massey LK, Mah AL, Ford DL, Miller J, Liang J, Doong H, Monteiro MJ: Overexpression of ubiquilin decreases ubiquitination and degradation of presenilin proteins. J Alzheimers Dis 2004, 6:79-92.

37. Heir R, Ablasou C, Dumontier E, Elliott M, Fagotto-Kaufmann C, Bedford FK: The UBL domain of PLIC-I regulates aggresome formation. EMBO Rep . 2006, Published online November 6th 
38. Iwata A, Riley BE, Johnston JA, Kopito RR: HDAC6 and microtubules are required for autophagic degradation of aggregated huntingtin. J Biol Chem 2005, 280:40282-40292.

39. Davidson JD, Riley B, Burright EN, Duvick LA, Zoghbi HY, Orr HT: Identification and characterization of an ataxin- I-interacting protein: AIUp, a ubiquitin-like nuclear protein. Hum Mol Genet 2000, 9:2305-23I2.

40. Riley $B E, X u Y$, Zoghbi HY, Orr HT: The effects of the polyglutamine repeat protein ataxin-I on the UbL-UBA protein AlUp. J Biol Chem 2004, 279:42290-4230I.

41. Kitada T, Asakawa S, Hattori N, Matsumine H, Yamamura $Y$, Minoshima S, Yokochi M, Mizuno Y, Shimizu N: Mutations in the parkin gene cause autosomal recessive juvenile parkinsonism. Nature 1998, 392:605-608.

42. Farrer $M$, Chan $P$, Chen $R$, Tan L, Lincoln S, Hernandez D, Forno L, Gwinn-Hardy K, Petrucelli L, Hussey J, Singleton A, Tanner C, Hardy J, Langston JW: Lewy bodies and parkinsonism in families with parkin mutations. Ann Neurol 200I, 50:293-300.

43. West $A B$, Maidment NT: Genetics of parkin-linked disease. Hum Genet 2004, I | 4:327-336.

44. Zhao J, Ren Y, Jiang Q, Feng J: Parkin is recruited to the centrosome in response to inhibition of proteasomes. J Cell Sci 2003 II 6:4011-4019.

45. Shimura H, Hattori N, Kubo S, Mizuno Y, Asakawa S, Minoshima S, Shimizu N, Iwai K, Chiba T, Tanaka K, Suzuki T: Familial Parkinson disease gene product, parkin, is a ubiquitin-protein ligase. Nat Genet 2000, 25:302-305.

46. Zhang Y, Gao J, Chung KK, Huang H, Dawson VL, Dawson TM: Parkin functions as an E2-dependent ubiquitin- protein ligase and promotes the degradation of the synaptic vesicle-associated protein, CDCrel-I. Proc Natl Acad Sci U S A 2000, 97:13354-13359

47. Imai Y, Soda M, Takahashi R: Parkin suppresses unfolded protein stress-induced cell death through its E3 ubiquitin-protein ligase activity. J Biol Chem 2000, 275:3566 I-35664.

48. Chung KK, Zhang $Y$, Lim KL, Tanaka $Y$, Huang $H$, Gao J, Ross CA, Dawson VL, Dawson TM: Parkin ubiquitinates the alpha-synuclein-interacting protein, synphilin-I: implications for Lewybody formation in Parkinson disease. Nat Med 200I, 7:II44-II50.

49. Imai Y, Soda M, Inoue H, Hattori N, Mizuno Y, Takahashi R: An unfolded putative transmembrane polypeptide, which can lead to endoplasmic reticulum stress, is a substrate of Parkin. Cell 200I, 105:89I-902.

50. Shimura H, Schlossmacher MG, Hattori N, Frosch MP, Trockenbacher A, Schneider R, Mizuno Y, Kosik KS, Selkoe DJ: Ubiquitination of a new form of alpha-synuclein by parkin from human brain: implications for Parkinson's disease. Science 200I, 293:263-269.

51. Staropoli JF, McDermott C, Martinat C, Schulman B, Demireva E, Abeliovich A: Parkin is a component of an SCF-like ubiquitin ligase complex and protects postmitotic neurons from kainate excitotoxicity. Neuron 2003, 37:735-749.

52. Sakata E, Yamaguchi Y, Kurimoto E, Kikuchi J, Yokoyama S, Yamada S, Kawahara H, Yokosawa H, Hattori N, Mizuno Y, Tanaka K, Kato K Parkin binds the Rpn 10 subunit of 265 proteasomes through its ubiquitin-like domain. EMBO Rep 2003, 4:30I-306.

53. Lim KL, Dawson VL, Dawson TM: Parkin-mediated lysine 63. linked polyubiquitination: A link to protein inclusions formation in Parkinson's and other conformational diseases? Neurobiol Aging 2006, 27:524-529.

54. Hofmann RM, Pickart CM: In vitro assembly and recognition of Lys-63 polyubiquitin chains. J Biol Chem 200I, 276:27936-27943.

55. Wang $\mathrm{Q}$, Young $\mathrm{P}$, Walters KJ: Structure of S5a bound to monoubiquitin provides a model for polyubiquitin recognition. J Mol Biol 2005, 348:727-739.

56. Weissman AM: Themes and variations on ubiquitylation. Nat Rev Mol Cell Biol 200I, 2:169-178.

57. Fallon L, Belanger CM, Corera AT, Kontogiannea M, Regan-Klapisz E, Moreau F, Voortman J, Haber M, Rouleau G, Thorarinsdottir T, Brice $A$, van Bergen En Henegouwen PM, Fon EA: A regulated interaction with the UIM protein Eps 15 implicates parkin in EGF receptor trafficking and PI(3)K-Akt signalling. Nat Cell Biol . 2006, Published online Jul $23^{\text {rd }}$
58. Henn IH, Gostner JM, Lackner P, Tatzelt J, Winklhofer KF: Pathogenic mutations inactivate parkin by distinct mechanisms. $J$ Neurochem 2005, 92: I I4-I 22.

59. Finney N, Walther F, Mantel PY, Stauffer D, Rovelli G, Dev KK: The cellular protein level of parkin is regulated by its ubiquitinlike domain. I Biol Chem 2003, 278:16054-16058.

60. Lonser RR, Glenn GM, Walther M, Chew EY, Libutti SK, Linehan WM, Oldfield EH: von Hippel-Lindau disease. Lancet 2003, 36 I:2059-2067.

61. Kaelin WG Jr: Molecular basis of the VHL hereditary cancer syndrome. Nat Rev Cancer 2002, 2:673-682.

62. Maxwell PH, Wiesener MS, Chang GW, Clifford SC, Vaux EC, Cockman ME, Wykoff CC, Pugh CW, Maher ER, Ratcliffe PJ: The tumour suppressor protein VHL targets hypoxia-inducible factors for oxygen-dependent proteolysis. Nature 1999, 399:27I-275.

63. Cockman ME, Masson N, Mole DR, Jaakkola P, Chang GW, Clifford SC, Maher ER, Pugh CW, Ratcliffe PJ, Maxwell PH: Hypoxia inducible factor-alpha binding and ubiquitylation by the von Hippel-Lindau tumor suppressor protein. J Biol Chem 2000, 275:25733-2574l.

64. Kamura T, Burian D, Yan Q, Schmidt SL, Lane WS, Querido E, Branton PE, Shilatifard A, Conaway RC, Conaway JW: MufI, a novel Elongin BC-interacting leucine-rich repeat protein that can assemble with Cul5 and $\mathrm{RbxI}$ to reconstitute a ubiquitin ligase. J Biol Chem 200I, 276:29748-29753.

65. Ng JM, Vrieling H, Sugasawa K, Ooms MP, Grootegoed JA, Vreeburg JT, Visser P, Beems RB, Gorgels TG, Hanaoka F, Hoeijmakers JH, van der Horst GT: Developmental defects and male sterility in mice lacking the ubiquitin-like DNA repair gene mHR23B. Mol Cell Biol 2002, 22: I 233-I245.

66. Goldberg MS, Fleming SM, Palacino IJ, Cepeda C, Lam HA, Bhatnagar A, Meloni EG, Wu N, Ackerson LC, Klapstein G], Gajendiran M, Roth BL, Chesselet MF, Maidment NT, Levine MS, Shen J: Parkin-deficient mice exhibit nigrostriatal deficits but not loss of dopaminergic neurons. J Biol Chem 2003, 278:43628-43635.

67. Itier JM, Ibanez P, Mena MA, Abbas N, Cohen-Salmon C, Bohme GA, Laville M, Pratt J, Corti O, Pradier L, Ret G, Joubert C, Periquet M, Araujo F, Negroni J, Casarejos MJ, Canals S, Solano R, Serrano A, Gallego E, Sanchez M, Denefle P, Benavides J, Tremp G, Rooney TA, Brice A, Garcia de Yebenes ]: Parkin gene inactivation alters behaviour and dopamine neurotransmission in the mouse. Hum Mol Genet 2003, I 2:2277-229I.

68. Lockhart PJ, O'Farrell CA, Farrer MJ: It's a double knock-out! The quaking mouse is a spontaneous deletion of parkin and parkin co-regulated gene (PACRG). Mov Disord 2004, 19:10I-104.

69. Pesah Y, Pham T, Burgess H, Middlebrooks B, Verstreken P, Zhou Y, Harding M, Bellen H, Mardon G: Drosophila parkin mutants have decreased mass and cell size and increased sensitivity to oxygen radical stress. Development 2004, | 3 |:2 | 83-2 | 94.

70. Richardson PG, Mitsiades C. Hideshima T, Anderson KC: Bortezomib: proteasome inhibition as an effective anticancer therapy. Annu Rev Med 2006, 57:33-47.

7I. Verma R, Peters NR, D'Onofrio M, Tochtrop GP, Sakamoto KM, Varadan R, Zhang M, Coffino P, Fushman D, Deshaies RJ, King RW: Ubistatins inhibit proteasome-dependent degradation by binding the ubiquitin chain. Science 2004, 306: I 17-120.

72. Isaacs JS, Jung YJ, Mimnaugh EG, Martinez A, Cuttitta F, Neckers LM: Hsp90 regulates a von Hippel Lindau-independent hypoxiainducible factor-I alpha-degradative pathway. I Biol Chem 2002, 277:29936-29944.

73. Isaacs JS, Xu W, Neckers L: Heat shock protein $\mathbf{9 0}$ as a molecular target for cancer therapeutics. Cancer Cell 2003, 3:2 I3-2I7.

74. Maloney A, Workman P: HSP90 as a new therapeutic target for cancer therapy: the story unfolds. Expert Opin Biol Ther 2002, 2:3-24.

\section{Publication history}

Republished from Current BioData's Targeted Proteins database (TPdb; $\underline{\text { http://www.targetedproteinsdb.com) }}$. 